\title{
Discussion on the Development of Urbanization in China from the Perspective of Ecological Civilization
}

\author{
Yuetao Wu \\ Xi’an Aeronautical University, Shaanxi, Xi’an, China, 710077
}

Keywords: ecological civilization; urbanization; issue; suggestion; development

\begin{abstract}
With the promotion of China's market economy and the vigorous propaganda of national policies of China, the living standard of Chinese people has gradually realized the level of a comfortable life, at the some time, the pace of urbanization in China has become faster and faster so that the material life and spiritual life of the people have been greatly improved. The development of urbanization is an important direction of social development in China, but during the development of urbanization, the environment has also been destroyed to some extent. Therefore, the developmental conception of ecological civilization is very important. This paper deeply analyzes several serious problems in the development of China's urbanization from the perspective of ecological civilization, and discusses suggestions for the development of China's urbanization from the perspective of ecological civilization.
\end{abstract}

As the rapid development of economy and society, people's way of life is changing, and people could enjoy a richer and more convenient life. However, the environmental pressure that comes from the process of economical development is also heavier and heavier; environment pollution has become one of the serious issues that block the development of urbanization. Based on this, in the construction and development of urbanization of China, it is necessary to be based on the current national conditions and environmental conditions, take ecological civilization as an important construction concept, and then, integrate the conception of ecological civilization with the politics, culture, economy, and social construction, so as to avoid the situation of resource shortage and environmental deterioration. From the perspective of ecological civilization, to construct a harmonious urbanization development could not only achieve the requests of scientific development and build a moderately prosperous society in all-round way, but also promote a harmonious relationship between the human and the nature, so as to promote human civilization and promote the sustainable development of global ecological environment.

\section{Problems in the Urbanization Development from Ecological Civilization in China}

The ultimate purpose of urbanization is to improve people's life quality, and promote all the people in China to enjoy a comfortable life. However, the construction of urbanization in different areas of China has caused the destruction to the ecological environment in which we live to some extent, so that the environment is being polluted and natural resources have been becoming scarce. This kind of urbanization is contrary to the original intention of China's urbanization development. Specifically, there are some prominent problems in the development of urbanization in China from the perspective of ecological civilization as below.

As the constant development of economy and industry, the gradual migration of rural population to cities is a very prominent phenomenon in the development of urbanization. The development of urbanization is not means constructing lots of building blindly, urban construction is one of the aspects of urbanization, and the conception of urbanization development is a systematic conception. In the actual development of urbanization, many areas exploit the land resources blindly, and the local land offices have not made a reasonable planning for the lands which will be exploited; unfortunately, they just extend the scope of the city by means of approving of exploiting the land resources blindly, and this shows their unscientific understandings about the development of urbanization $^{[1]}$. The developmental process of urbanization should advance in regular order, it must 
consider the actual economic situation, land resources situation of a city, and then, to exploit the resources and construct the buildings according to the scientific planning so as to promote the development of economy.

In the rapid development of urbanization, the ecological environment becomes worse and worse, a lot of issues about environmental pollution should be solved. For example, some problems, which we have experienced such as the greenhouse effect in city, fog and haze, white pollution, and automobile exhaust pollution, etc, make the air quality in city worse and worse. In the development of many cities, the local governments just pay attention to the increasing of GDP but the harmonious development of the economy and environment; they are fond of vanity project but ignore the environment; they emphasize the speed of development but neglect the environment protection or want to improve the environment later. In general, the development of urbanization in many areas of China is based on the consumption of the environment; this kind of development is unsustainable.

In the development of urbanization of China, the conception of saving energy and resources is weak, the resources are used inefficiently, the utilization rate of energy is high, and the techniques used in the construction is backward, these all lag behind the developed countries. In addition, because China has a large population, the per capita of energy is lower, at the some time, the resources are hard to exploit, and the cost of exploiting is also very high, so we have to worry about the sustainable development of urbanization and ponder over the corresponding measures of optimization. From the current situation of urbanization, the population of China is constantly assembling in city, more and more Chinese families have their new automobiles, and the domestic petroleum resource can not meet the need of people in China, so that the amount of imported oil is increasing, and the extent of dependence on oil is also increasing. In the aspect of water resources, the pollution of urban construction to water resources is also very serious. The unscientific discharge of industrial wastewater and domestic sewerage lead to the available water in cities becomes less and less, and the decrease of water resources and water quality is very obvious ${ }^{\text {[2] }}$. In the aspect of forest, the deforestation caused by urban construction is also very serious, although people increase the area of green land gradually, but the value of artificial green land is much less than the natural forest.

For achieving a harmonious urban development in the perspective of ecological civilization, first of all, we must make an all-round and harmonious planning; but form the current situation of development, the urban development is lack of scientific and harmonious planning. In the three major industries, industrial development can not be separated from the support of energy, so the massive development of it causes serious pollution and damage to the ecological environment. In the current urban development of China, we pay great attention to the development of the primary industry, however, the development of the third industry is neglected, which leads to the problem of uncoordinated development of the industrial chain during the process of urbanization, and it makes the resources are seriously wasted and the quality of the environment decrease constantly. What's more, most of the city have not make a all-round, long-term, scientific, and reasonable planning for the urbanization, so that the phenomenon that the urban construction is inefficient or futile is very common, and this kind of construction would cause the environment pollution and destruction many times ${ }^{[3]}$.

\section{Suggestions for the Urbanization Development of China from Ecological Civilization in China}

Urbanization development must adhere to the conception of sustainable development, accelerate the pace of upgrading and the speed of development, high speed of the development is the important foundation of urban development, and the some time, we must pay more attention to the understanding and implementation of ecological development conception, so as to construct a harmonious and perfect developmental system of ecological civilization and actively explore the developmental method of ecological civilization. It is necessary to highlight the upgrading of the developmental conception, innovation of the system, and the upgrading of technology, so as to 
achieve the ultimate objective of socialist ecological civilization, and to construct the urban cultural system, the human settlement system, the economic operation system, and the environment protection system according to the ecological civilization development. To take the advantage of scientific and reasonable developmental conception, and keep a kind of harmonious relationship between environment protection and the development of urbanization ${ }^{[4]}$. For example, to promote the development of organic agriculture energetically. To have a good understand of the ecological developmental conception could not only teach us to improve the using rate of the materials in the process of urbanization, but also provide the scientific guidance to the development of economy and promote the sustainable development of China in the aspects of economy and society.

The construction of ecological civilization is a long-term project, and it also need the attention of the public, it is a necessary factor to achieve the ecological civilization. So, all the people should make contributions to the development of ecological civilization, and become a constructor, at the some time, the government also should undertake the duty of calling for the ecological civilization construction, and let every citizen go along with the developmental conception of ecological civilization, and undertake the duty of ecological civilization ${ }^{[5]}$. The government can propagandize the knowledge about environment protection and the conception of ecological civilization so as to improve the environment thoughts of the public; the public also should be endowed the right of supervision, and then the public can have a further understand of civilization development.

In the process of urbanization, it should not only adjust the industrial structure reasonably, but also transit and upgrade the industrial structure, so as to promote the development of the new industry that could not only earn more benefit in shorter time, but also decrease the consumption of resources and energy, so as to achieve the harmonious society of environment friendly. Therefore, we must present the higher requests to the developmental speed and the standard of urbanization. It is important to adjust the administrative area of the villages and towns, and accelerate the speed of urbanization. In addition, assembling the separated small industrial units together, and provide the supports to the small units, and then, to transit the small units to the high-tech industries, so as to promote the development of transition and upgrading of the cities ${ }^{[6]}$. At last, adopting the brand new ways of development for promoting the development of the cities. It is important to construct the different areas with different functions and assemble the human resource and other resources for the development of the cities.

In legal society, the law is the powerful guarantee for protecting the justifiable right of all people, when the material life of people becomes richer and richer, their ecological benefit becomes more and more important, the ecological benefit should be protected by the law, and the environment would be protected. Therefore, in the development of urbanization from the perspective of ecological civilization, it is necessary to strengthen legislation and enforcement of ecological protection. The local government should make the relevant laws that are fit for the local situations, and emphasize the construction of low carbon economy, at the some time, strengthen the enforcement., and improve the access mechanism for environment protection. If a new project will be established, it must fit the requirement of environment protection, if it is not fits the requirement, it must be cancel. We also can adopt some special actions for find the activities of polluting the environment and punish the relevant person liable.

The innovation of system is also very important to the urbanization development from the perspective of ecological civilization, and to improve the harmony between inner and out control of environment protection. Form the perspective of ecological civilization, the construction of urbanization system should be objective and fair, and should innovate the developmental system. We must innovate the compensation mechanism of ecology, and set up some trial protective area such as the drinking water source site, forest, basin of river, natural protective area, etc. and set up the mechanism of evaluating environmental pollution and compensation. It is also important to choose a proper person who is responsible for protecting the environment of a certain area, and to organize the certain institution that is authorized by the government to protect the environment for business benefit. 


\section{Conclusion}

In the process of urbanization, environment pollution has become a serious problem, the government, society, and every citizen should make contributions to the sustainable development actively, so as to promote the transition and upgrading of the urbanization in China. Therefore, the government and the relevant construction departments should understand the conception of ecological civilization well and implement it well, propagandize the scientific conception to the public, pay more attention the industrial transition and upgrading in the development of urbanization, and establish the all-round, scientific system for the construction of ecological civilization, so as to promote a effective, environmental, and sustainable development of urbanization of China.

\section{Acknowledgements}

Study on the Planning and Development Mode of the Second - tier Cities Fringe Area in Shaanxi Province (Grant No.2016D051).

\section{References:}

[1] Hu Jing. Analysis on New Kind of Urbanization Based on Ecological Civilization[J] China Housing Facilities, 2017, (01): 64-65.

[2] Hua Weiyi. Research on the Harmonious Development between the Urbanization and Environment Protection from the Perspective of Ecological Civilization[J]. Environment and Development, 2017, (01):50-58.

[3] Bi Guohua, Yang Qingyuan, Liu Su. On the Coupling and Harmonious Development Between the Ecological Civilization Construction and the Urbanization of the Provinces in China[J]. Economic Geography, 2017, (01):50-58.

[4] Cheng Songtao. Spatial difference Analysis and unity discussion on the Developmental level of Ecological Civilization in China[J]. Reform \& Opening, 2016, (24):19+21.

[5] Yu Li. Deliberation and Theoretical Exploration of "Ecological Civilization" and the New Urbanization[J]. Urban Studies, 2016, (01):19-26.

[6] Zhang Zubai. Research on the Blocks and the Countermeasures in the Process of Urbanization[J]. Journal of Anhui Polytechnic University, 2015, (06):5-8. 